\title{
A new method for Espresso Coffee brewing: Caffè Firenze
}

\author{
Alessandro Parenti, Lorenzo Guerrini, Piernicola Masella, Riccardo Dainelli, Paolo Spugnoli \\ Dipartimento di Gestione dei Sistemi Agrari, Alimentari e Forestali, Università di Firenze, Italy
}

\begin{abstract}
Espresso coffee is the most popular choice for Italian coffee consumers. It has been estimated that every day, in the world, over of 50 million of Espresso cups are taken. As a consequence of this success, a large number of devices to make Espresso have been developed. In this scenario, a new device has been recently developed and patented (Eu. Patent 06023 798.9; US 2010/0034942 A1). This brew method, named "Caffè Firenze", uses a sealed extraction chamber, where water and gas provides pressure higher than the other extraction methods. Three main parts compose the apparatus: the gas source, the extraction chamber and the heat exchanger. The gas source provides the pressured gas required to raise the pressure of the system. The extraction chamber is made with chrome-brass and accessorized with two heating glow plugs. Many are the factors affecting Espresso quality: it is known that, coffee type, roasting conditions and degree, grinding and storage strongly affect the obtained brew. Also, several studies have been carried out on the effect of the setting parameters on quality, for example water pressure, water temperature, and brew time. Among the characteristics that determine Espresso quality, the main attribute for the visual analysis is, without doubts, the foam, also called "crema". Indeed, height, aspect, and persistency of foam are features much appreciates by consumers. Two distinguish Espresso foam parameters are the persistency and foam index. Equipping a commercial bar machine with the new designed extraction chamber makes feasible the comparison between the traditional way to brew Espresso and the new device. The comparison was made holding the previous mentioned conditions, and differences were evaluated in terms of
\end{abstract}

Correspondence: Lorenzo Guerrini, Dipartimento di Gestione dei Sistemi Agrari, Alimentari e Forestali, Università degli Studi di Firenze, Piazzale delle Cascine 15, 50144, Firenze (Italy).

Tel.+39.0553288352 - Fax: +390553288316 .

E-mail lorenzo.guerrini@unifi.it

Key words: coffee extraction method, coffee foam, coffee device

Contributions: the authors contributed equally.

Conflict of interests: the authors declare no potential conflict of interests.

Funding: the work was supported by La Marzocco s.r.l. and Francesco Illy.

(C) Copyright A. Parenti et al., 2013

Licensee PAGEPress, Italy

Journal of Agricultural Engineering 2013; XLIV(s2):e52

doi:10.4081/jae.2013.s2.e52

This article is distributed under the terms of the Creative Commons Attribution Noncommercial License (by-nc 3.0) which permits any noncommercial use, distribution, and reproduction in any medium, provided the original author(s) and source are credited. physical parameters and aromatic profiles.

Caffè Firenze shows pronounced differences compared with traditional Espresso in term of foam-related parameters. Also, the new extraction device produces coffees with higher values of body-related parameters, such density and viscosity. The two kinds of Espressos are perceived different at visual analysis and taste by a panel test.

\section{Introduction}

Espresso coffee (EC) is a popular choice of coffee consumers. Illy et al. (2005) estimate that, every day in the world, over of 50 million of EC cups are taken, and in the same work, give EC definition as "a brew obtained by percolation of hot water under pressure through tamped/compacted roasted ground coffee, where the energy of the water is spent within the cake". For this reason, a large number of devices and methods to produce EC are known. The conventional way to brew EC is the bar machine. This device consists of three main parts: a rotative pump, a heat exchanger, and an extraction chamber (Illy et al., 2005). It is known that, coffee type, roasting conditions and degree (Sanz et al., 2002), grinding and storage (Anese et al., 2006) strongly affect EC quality. Also, several studies have been carried out on the effect of the setting parameter on brew quality, for example water pressure (Andueza et al., 2002), water temperature (Andueza et al., 2003) and brew time (Ludwig et al., 2012). Hence, the brew could be considered as influenced by several factors and the overall quality of the EC is hardly predictable.

Among the characteristics that determine EC quality, the main attribute for the visual analysis is without doubts the foam, also called "crema" (Illy et al., 2005). In fact an expert consumer can immediately detect from foam colour, texture and persistency dissimilarity possible errors in grinding, percolation, temperature or extraction level (Illy and Navarini, 2011). Physically the crema is a biphasic system compounded by a gas phase surrounded by a liquid phase, named lamellae. The gas phase is compounded by the carbon dioxide originated during roasting and the water vapour made during the percolation process. During the percolation, the hot water flows through the grounded coffee panel, solubilizing and emulsifying proteins and low-molecular weight surfactant, which are responsible for the physical properties of the crema. Particularly some of the oils are emulsified by the pressure provided by the espresso machine and give the creamy sensation of the foam (Piazza et al., 2008). Two distinguish EC foam features are the persistency and foam index. The latter is defined as the ratio between the foam and liquid volumes; this index should be, for a quality EC, at least $10 \%$. Persistency is defined as the time before foam breaking up and the underlying brown liquid phase became visible. This shouldn't happen before two minutes since the EC was brewed (Illy et al., 2005). Since height, aspect and persistency of foam are much appreciate by consumers, a new device able to improve these characteristic have been recently developed and patented (Eu. Patent 06023 798.9; US 2010/0034942 A1). This brew method, named "Caffè Firenze" (CF), uses a sealed extraction chamber where water and air provides pressure higher than the other extraction methods. For better understand- 
ing the physical and the chemical difference of EC brewed with this technique, $\mathrm{CF}$ was compared with a Bar Machine (BM), the traditional way to produce EC.

\section{Materials and Methods}

\section{Caffè Firenze method description}

The method for preparing CF could be summarized in four subsequent main steps. First, $7 \mathrm{~g}$ of grinded coffee are added to the extraction chamber, which is sealed. Than, pressurized air is introduced to the system. In this process the pressure rises until 15 bar. Afterward, hot water is introduced in the chamber. The water further comprises the gas, and pressure reach 20 bar. After a pre-infusion phase of $10 \mathrm{~s}$, the coffee flows out.

\section{Device description}

To perform the tests a commercial bar machine (Strada, La Marzocco, Italy) was modified, replacing one of the brewing chambers with a Caffè Firenze chamber. The new bar machine arrangement is shown in Figure 1.

The CF group is made in AISI 316 steel, with an internal chamber volume of about $200 \mathrm{~cm}^{3}$.

The cylinder has internal diameter of $49 \mathrm{~mm}$, and support the air and the water entries. The external cylinder is provided with three thermo resistances thermometer managed with a PID. A compressor provides the required air pressure.

\section{Coffee}

The tests were performed (nine replicates per treatment) using a commercial blend (Amici Red, 100\% arabica). For every coffee a single serving pod was used. This to minimize the impact of the milling, storage, and dosing related parameters.

All brewed coffees were immediately sampled at the outflow from the machines in a glass weighing bottle (named sampling vessel, $75 \mathrm{ml}$ volume, $53 \mathrm{~mm}$ of internal diameter and $34 \mathrm{~mm}$ of height). With the purpose of homogeneity, the ECs were sampled by targeting at the same weight of percolated liquid into the sampling vessel, regardless the coffee flow rate or percolation time. Thus, a digital balance (max capacity $300.0 \mathrm{~g}$; precision $0.1 \mathrm{~g}$, D-mail srl, Italy,) was placed under the vessel and the coffee collected until the preselected weight of $25 \mathrm{~g}$. The resulting final brew weight was of $25.7 \pm 0.6 \mathrm{~g}$ averaged over all the samples.

All the sampled ECs were analyzed and evaluated for the following parameters.

Foam Index and persistency: Foam index is defined as the ratio between foam and liquid volume (vol vol-1 \%) measured $30 \mathrm{~s}$ after the extraction (geometry of the sampling vessel as above reported). Persistency is defined as the time (in minutes) before foam breaking, leaving a first uncovered black spot on the surface of the beverage (Petracco, 2001).

Density and viscosity: Before performing these measurements samples were cooled to $20^{\circ} \mathrm{C}$. Density was measured with a pycnometer (g ml-1) with $25 \mathrm{ml}$ of capacity. Viscosity was measured with a capillary viscometer (Ostwald) fitted with an automatic optical reader (model Viscoclock, SCHOTT Instruments GmbH, Germany) and expressed as $\mathrm{mN} \mathrm{s} \mathrm{m-2.}$

Panel test: the sensorial characteristics were evaluated with a descriptive and quantitative analysis. Nine people made up the panel. On the evaluation sheet, each panellist had to report the following features on a straight line of $20 \mathrm{~cm}$ of length:

- visual: foam amount, colour; olfactory: fresh fragrances, toasted fragrances;

gustatory: body, bitter, sweet, sour, salty, umami, astringency, persistency, burned;

- a global evaluation.

\section{Results and Discussion}

The Caffè Firenze brewing method produces a well-characterized EC, as shown in Figure 2.

The first noticeable distinctive trait is the foam amount and its persistency. The traditional bar method return a foam index value, in the experimental conditions, of $32.4 \pm 7.3$, three times higher to the literature reference minimum value for EC quality of $10 \%$. The foam index obtained with $\mathrm{CF}$ brewing method is $117.6 \pm 21$.7. Hence, at a visual analysis the difference between the traditional EC and CF results immediately clear, because of the different foam/liquid ratio. Even the

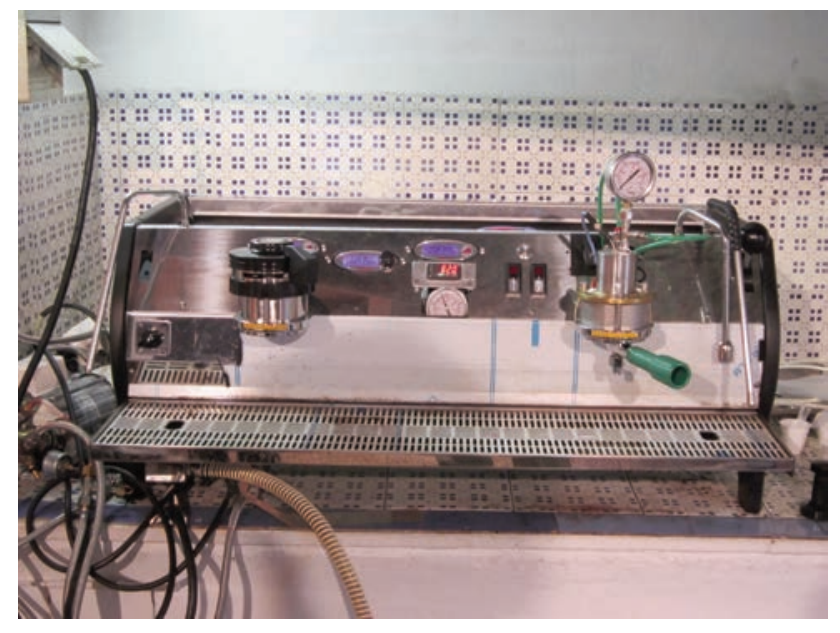

Figure 1. Modified "Strada" Bar Machine. The left brewing chamber is the standard equipment; the right one is the Caffè Firenze device.

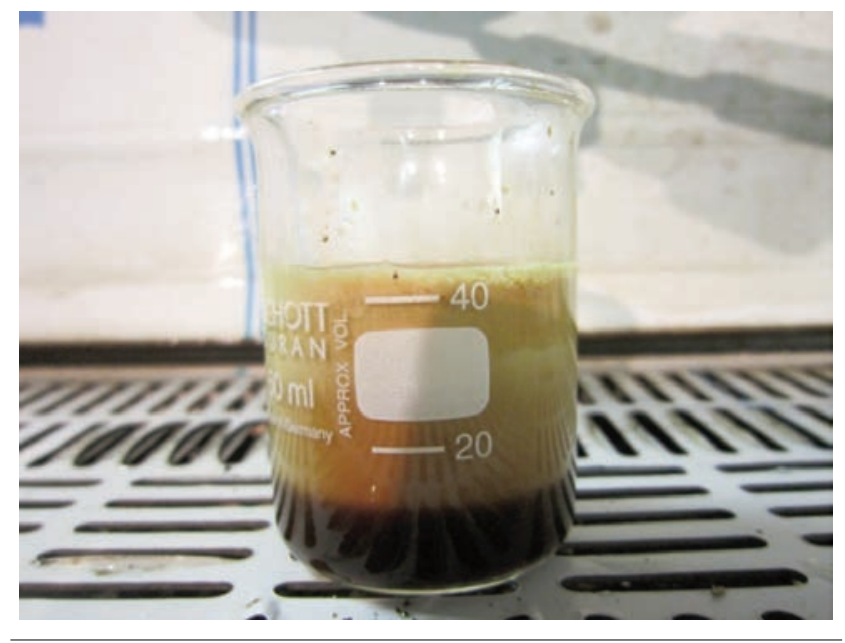

Figure 2. Caffè Firenze. 


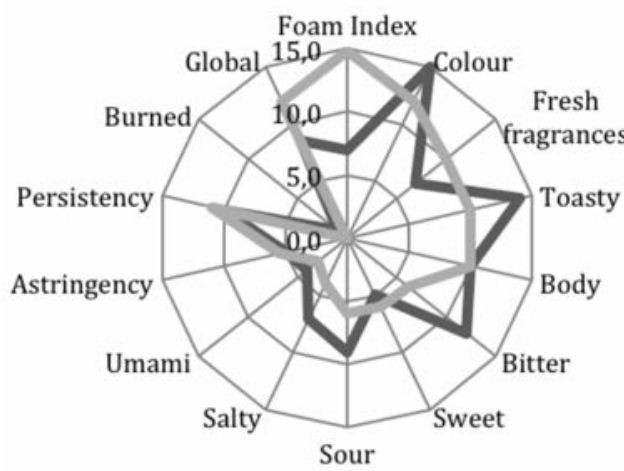

Figure 3. Sensorial profile of the two kinds of Espresso.

Table 1. Measured density and viscosity of produced espresso coffee. Different letters indicate significant difference at $t$-test $(p=0.05)$.

\begin{tabular}{lcc} 
& Bar method & Caffè Firenze \\
Density (g ml-1) & $1.026 \mathrm{~b}$ & $1.057 \mathrm{a}$ \\
Viscosity (mNm-2s) & $1.38 \mathrm{~b}$ & $1.59 \mathrm{a}$ \\
\hline
\end{tabular}

persistency of the foam is higher in CF than EC. In the EC the first black spot of liquid uncovered with foam appear after $3.88 \pm 0.93 \mathrm{~min}-$ utes, greater than the literature value of two minutes too. Instead, CF shows a foam persistency larger than 8 hours. Even these data indicates a good EC quality in term of foam related parameters; $\mathrm{CF}$ is immediately recognisable at visual analysis for the greater amount of foam and its persistency. The difference produced with the two different brewing methods could be also noticed in term of two body-related physical parameters, such as density, and viscosity, as seen in table 1.

Even in this case the traditional EC shows significant lower value (ttest, $\mathrm{p}=0.05$ ) than the $\mathrm{CF}$. However, the less value of $\mathrm{BM}$ in the body related parameters was not perceived by panel test. In fact, for both ECs, the body score were 10/20. The results of the descriptive sensorial analysis are reported in Figure 3. At visual analysis, panellists notice the already mentioned difference in foam index and some differenced in colour. In fact, CF is characterized by light brown foam and a dark brown, while BM shows the typical hazelnut foam with the tiger skin effect. CF taste results less intense in term of physical sensations such as bitter, acid, and umami than BM. Also, CF reveals less pronounced burned-roasty flavour. Otherwise, panellist perceived more fresh fragrances such as flower and hazelnut scents. As global evaluation panellists prefer $\mathrm{CF}$ respect to $\mathrm{BM}$.

\section{Conclusion}

The new device for Espresso Coffee brew is able to produce a welldefined kind of coffee, named Caffè Firenze. This coffee is recognisable at a visual analysis because of the large amount of light brown foam on top of the beverage. Furthermore, the performed panel tests and the analysis of density and viscosity highlight additional difference between the two kinds of Espressos. Eventual, on the basis of the global evaluation on panel tests a hypothetical consumer acceptance of this product should be imagined.

\section{References}

Andueza, S., Maeztu, L., Dean, B., De Peña, M. P., Bello, J., \& Cid, C. (2002). Influence of water pressure on the final quality of arabica espresso coffee. Application of multivariate analysis. Journal of agricultural and food chemistry, 50(25), 7426-31.

Andueza, S., Maeztu, L., Pascual, L., Ibanez, C., De Peña, M. P., Cid, C., $\&$ N. (2003). Influence of extraction temperature on the final quality of espresso coffee. Journal of the Science of Food and Agriculture, 83(3), 240-248.

Anese, M., Manzocco, L., \& Nicoli, M. C. (2006). Modeling the secondary shelf life of ground roasted coffee. Journal of agricultural and food chemistry, 54(15), 5571-6.

Illy, E., \& Navarini, L. (2011). Neglected Food Bubbles: The Espresso Coffee Foam. Food biophysics, 6(3), 335-348.

Illy A., Viani R., \& Suggi Liverani F., (2005). Espresso coffee: the science of quality. Elsevier Academic Press.

Ludwig, I. A., Sanchez, L., Caemmerer, B., Kroh, L. W., De Peña, M. P., \& Cid, C. (2012). Extraction of coffee antioxidants: Impact of brewing time and method. Food Research International, 48(1), 57-64.

Piazza, L., Gigli, J., \& Bulbarello, A. (2008). Interfacial rheology study of espresso coffee foam structure and properties. Journal of Food Engineering, 84(3), 420-429.

Petracco M., (2001). Technology IV: Beverage preparation: brewing trends for the new millennium, in Coffee recent development Ed by Clarke R. J. and Vitzthum 0. G., Blackwell Science, Oxford, pp 140164.

Sanz, C., Maeztu, L., Zapelena, M. J., Bello, J., \& Cid, C. (2002). Profiles of volatile compounds and sensory analysis of three blends of coffee: influence of different proportions of Arabica and Robusta and influence of roasting coffee with sugar. Journal of the Science of Food and Agriculture, 82(8), 840-847. 